\title{
Histological and immunohistochemical evaluation of epithelial and mesenchymal tumors of psittacines")
}

\author{
OZGE ERDOGAN BAMAC, S. SECKIN ARUN* \\ Istanbul University Cerrahpasa, Faculty of Veterinary Medicine, Turkey \\ *Vetlab Veterinary Laboratory, Istanbul, Turkey
}

Erdogan Bamac O., Arun S. S.

\section{Histological and immunohistochemical evaluation of epithelial and mesenchymal tumors of psittacines}

\section{Summary}

This study describes histological and immunohistochemical evaluation of 50 epithelial and mesenchymal tumors of psittacines that were found in the archives of the pathology departments of veterinary faculties at Utrecht University and Istanbul University Cerrahpasa. In each case, cellular morphological features, tumoral pattern and mitotic activity were evaluated histologically, and immunohistochemistry was performed by the streptavidin-biotin immunoperoxidase method using a panel of commercially available antibodies raised against pan-cytokeratin, vimentin, muscle-specific actin, desmin, smooth muscle actin and Factor VIII/von Willebrand Factor. The histological evaluation revealed that 30 epithelial tumors were squamous cell carcinoma (n: 20), renal adenocarcinoma (n:3), basal cell carcinoma (n: 2), abdominal carcinoma (n: 2), uropygial gland carcinoma (n: 1), cloacal carcinoma (n: 1) and cholangiocarcinoma (n: 1). Out of the 50 tumors, 13 had a mesenchymal origin and were diagnosed as fibrosarcoma (n: 4), hemangioma (n: 3), hemangiosarcoma (n: 4) and leiomyosarcoma (n: 2). Histological diagnosis could not be made for 7 tumors, and they were evaluated as undifferentiated malignant tumors (UDMT). Two tumors diagnosed as fibrosarcoma and three tumors diagnosed as UDMT showed strong SMA staining and were re-diagnosed as leiomyosarcoma. In view of the IHC findings, two other UDMTs were re-diagnosed as fibrosarcoma and anaplastic carcinoma. Although only a limited number of antibodies were used in the control panel, they were useful in establishing a definite diagnosis in some cases.

Keywords: psittacine, epithelial-mesenchymal tumors, histology, immunohistochemistry

Various epithelial and mesenchymal tumors have been reported in psittacine birds up to date $(1,3,15$, 21). Squamous cell carcinomas and renal carcinomas are the most frequent among epithelial tumors (7, $18,22)$, while fibrosarcomas are the most commonly reported mesenchymal tumors (13). As more cases are reported, more valuable information about tumor behavior will become available (6).

The aim of this study is to provide a histological characterization of epithelial and mesenchymal tumors of psittacines and to describe the immunohistochemical profiles of those tumors by comparing and correlating their immunohistochemical features with findings of the initial histological examination of hematoxylineosin-stained sections by light microscopy.

1) This study was supported by the Research Fund of Istanbul University Cerrahpasa. Project number: T-443/0803200 and TUBITAK International Research Fellowship Programme 2214 (for PhD students). It was summarized from the $\mathrm{PhD}$ thesis of the first author.

\section{Material and methods}

The study was carried out on material from 50 tumor cases among psittacines that was found in the archives of Utrecht University, Veterinary Faculty, Pathobiology Department, the Netherlands and Istanbul University - Cerrahpasa, Veterinary Faculty, Pathology Department, Turkey over a 10-year period. Out of 50 birds, 25 were female and 13 were male. The sex of 12 birds was not reported.

Tumor tissues were previously fixed in $10 \%$ buffered formalin, embedded in paraffin and sectioned at $4 \mu \mathrm{m}$ for light microscopy. In re-assessment of conventional diagnosis based on hematoxylin-eosin staining, cellular morphological features, tumoral pattern and mitotic activity were evaluated in each case.

Immunohistochemistry (IHC) was performed by the streptavidin-biotin-immunoperoxidase technique on formalin-fixed paraffin-embedded specimens. A commercially available kit (Ultravision Large Volume Detection System, Lab Vision, USA, TP-125-HL) served as the detection 
Tab. 1. Tumor markers used in the study

\begin{tabular}{|c|c|c|c|c|c|c|c|c|}
\hline \multirow{2}{*}{ Catalogue code } & \multicolumn{2}{|c|}{ Tumor markers } & \multirow{2}{*}{ Clone } & \multirow{2}{*}{ Dilution } & \multirow{2}{*}{$\begin{array}{l}\text { Antigen retrieval } \\
\text { (enzyme) }\end{array}$} & \multirow{2}{*}{$\begin{array}{l}\text { Incubation } \\
\text { temperature }\end{array}$} & \multirow{2}{*}{$\begin{array}{l}\text { Incubation } \\
\text { period }\end{array}$} & \multirow{2}{*}{ IHC location } \\
\hline & Antibody* & Animal** & & & & & & \\
\hline $\begin{array}{l}\text { MP-Biomedicals, Solon, Ohio } \\
68120 \text { (1 ml) }\end{array}$ & Pan Cytokeratin & Rabbit (Pab) & - & $1: 1000$ & $\begin{array}{l}\text { Pronase }+37^{\circ} \mathrm{C} \\
10 \mathrm{~min}\end{array}$ & $+4^{\circ} \mathrm{C}$ & Overnight & Cytoplasmic \\
\hline $\begin{array}{l}\text { NeoMarkers, Fremont, CA } \\
\text { MS-129-P (1 ml) }\end{array}$ & Vimentin & Mouse (Mab) & V9 & $1: 50$ & $x$ & $+4^{\circ} \mathrm{C}$ & 1 Hour & Cytoplasmic \\
\hline $\begin{array}{l}\text { Euro Diagnostics, Apeldoorn, } \\
\text { the Netherlands } \\
\text { PDE-2203 (1 ml) }\end{array}$ & Desmin & Rabbit (Pab) & D33 & $1: 40$ & $x$ & Room Temp. & 1 Hour & Cytoplasmic \\
\hline $\begin{array}{l}\text { NeoMarkers, Fremont, CA } \\
\text { MS-21-P (1 ml) }\end{array}$ & SMA & Mouse (Mab) & $1 \mathrm{~A} 4$ & $1: 200$ & $x$ & Room Temp. & 1 Hour & Cytoplasmic \\
\hline $\begin{array}{l}\text { NeoMarkers, Fremont, CA } \\
\text { MS-742-S (1 ml) }\end{array}$ & MSA & Mouse (Mab) & HHF35 & $1: 100$ & $x$ & Room Temp. & 1 Hour & Cytoplasmic \\
\hline $\begin{array}{l}\text { DAKO, Carpinteria, CA } \\
\text { A } 082 \text { ( } 2 \text { ml) }\end{array}$ & F-VIII ra & Rabbit (Pab) & - & $1: 100$ & $\begin{array}{l}\text { Pronase }+37^{\circ} \mathrm{C} \\
10 \mathrm{~min}\end{array}$ & $+4^{\circ} \mathrm{C}$ & Overnight & Cytoplasmic \\
\hline
\end{tabular}

Explanations: *MSA - Muscle Specific Actin; SMA - Smooth Muscle Actin; **Pab - Policlonal Antibody; Mab - Monoclonal Antibody; $\mathrm{x}$ - no pretreatment required

system. Immunostaining was visualized with 3-amino9-ethylcarbozole (AEC LabVision, USA, TA-125-HA) for tissues that were marked with smooth muscle actin (SMA) and muscle-specific antibody (HHF35). Diaminobenzidine (DAB) (Lab Vision, USA, TA-125-HD) was used for tissues that were marked with pan-cytokeratin, vimentin, desmin and Factor VIII/von Willebrand Factor (F-VIII). Serial sections of each tumor tissue were treated with a panel of antibodies as described in Table 1.

\section{Results and discussion}

This is a comprehensive documentation of epithelial and mesenchymal tumors from 50 psittacine birds. Most of the tumors were found in African grey par-

Tab. 2. Tumor types and species of birds

\begin{tabular}{|c|c|c|c|c|c|c|c|c|c|c|}
\hline \multirow{2}{*}{ Tumor type } & \multirow{2}{*}{$n^{*}$} & \multicolumn{9}{|c|}{ Species of birds*** } \\
\hline & & A.G.P & B.F.A.P & B.Y.M & Budg. & C.F.M & G.W.M & M.L.B. & O.W.A & P.F.L \\
\hline Basal cell carcinoma & 2 & - & - & 1 & 1 & - & - & - & - & - \\
\hline Squamous cell carcinoma & 20 & 9 & 3 & - & 2 & 1 & - & - & 4 & 1 \\
\hline Renal adenocarcinoma & 3 & - & - & - & 3 & - & - & - & - & - \\
\hline Abdominal carcinoma & 2 & 1 & - & - & - & - & - & 1 & - & - \\
\hline Uropygial carcinoma & 1 & 1 & - & - & - & - & - & - & - & - \\
\hline Cloacal carcinoma & 1 & 1 & - & - & - & - & - & - & - & - \\
\hline Cholangiocarcinoma & 1 & - & - & 1 & - & - & - & - & - & - \\
\hline Anaplastic carcinoma & 1 & 1 & - & - & - & - & - & - & - & - \\
\hline Fibrosarcoma & 3 & 1 & - & - & 1 & 1 & - & - & - & - \\
\hline Hemangioma & 3 & 1 & - & - & 2 & - & - & - & - & - \\
\hline Hemangiosarcoma & 4 & 1 & - & - & 1 & - & - & - & 2 & - \\
\hline Leiomyosarcoma & 7 & 2 & - & - & 3 & - & 1 & - & 1 & - \\
\hline UDMT* * & 2 & - & - & - & 1 & - & - & - & 1 & - \\
\hline
\end{tabular}

Explanations: $\mathrm{n}^{*}$ - number; UDMT** - undifferentiated malign tumor. Species of birds***: A.G.P-African grey parrot (Psittacus erithacus), B.F.A.P - blue-fronted Amazon parrot (Amazona aestiva), B.Y.M - blue and yellow macaw (Ara ararauna), Budg. - budgerigar (Melopsittacus undulates), C.F.M - chestnut-fronted macaw (Ara severa), G.W.M - green-winged macaw (Ara choloroptera), M.L.B - masked lovebird (Agapornis personata), O.W.A - orange-winged Amazon (Amazona amazonica), P.F.L - peach-faced lovebird (Agapornis roseicollis) rots, with an incidence of $34 \%(17 / 50)$, followed by the budgerigars, with an incidence of $28 \%(14 / 50)$. The most common tumor sites were wings $(26 \%)$, extremities $(16 \%)$, the base of the tail $(14 \%)$ and the kidneys $(6 \%)$. Tumor types and the species of the birds are presented in detail in Table 2.

Histological evaluation revealed that 30 out of the 50 tumors were epithelial tumors. A total of 7 different types of epithelial tumors were diagnosed. Squamous cell carcinoma (SCC) was diagnosed in 20 birds, and it was the most commonly diagnosed type, constituting more than half of the epithelial tumors. SCC has been reported in many species of psittacine birds $(7,9-11)$, and in the present study the African grey parrot was the most affected species, followed by the orangewinged Amazon. Histological examination usually showed uniform squamous cells with large vesicular nuclei and abundant eosinophilic cytoplasm. Laminated keratin pearls were observed within epithelial islands in most of the cases (Fig. 1A). The sites and histological features of SCCs in this study correlate well with previous studies.

Renal adenocarcinoma is the most 


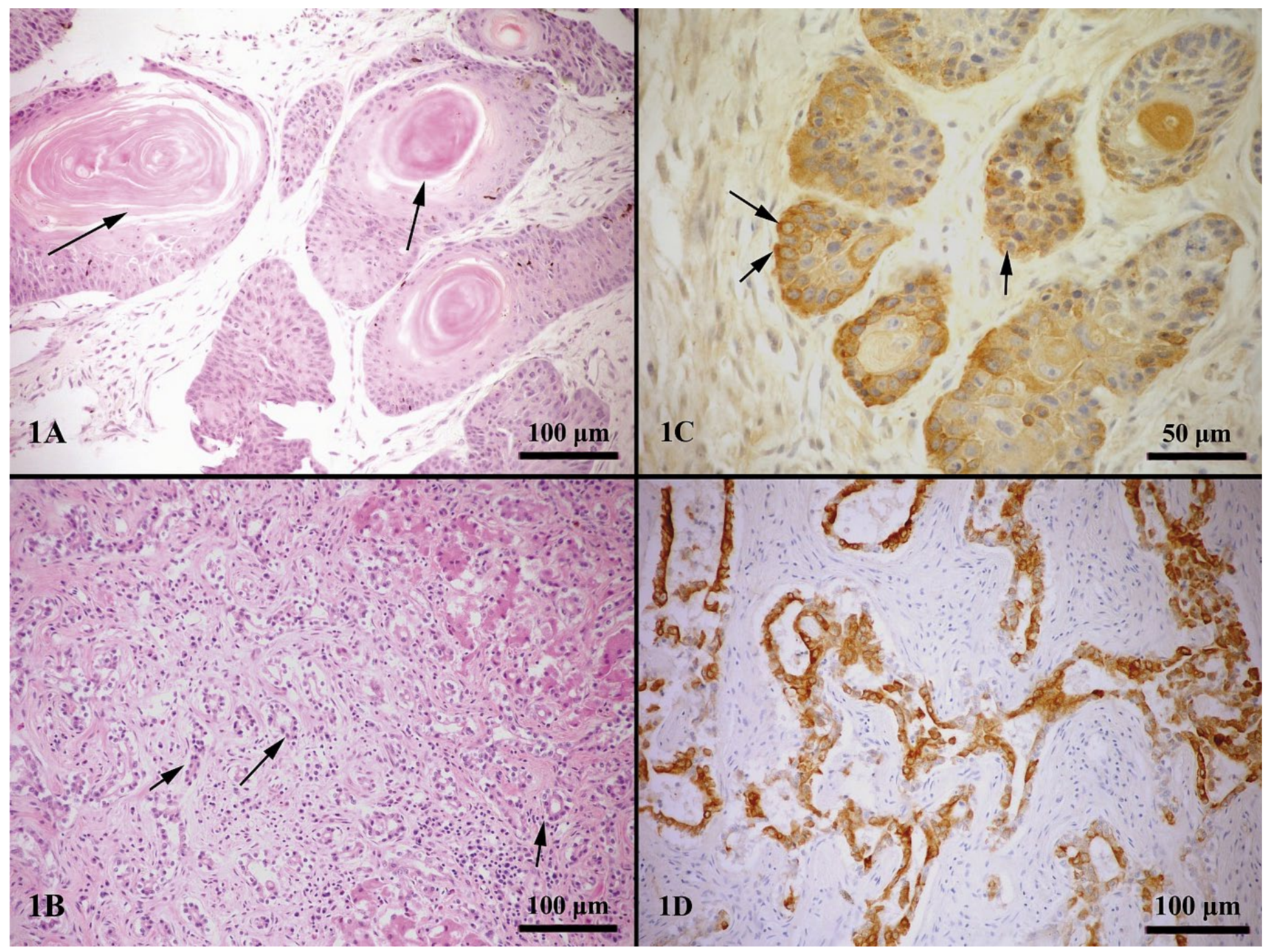

Fig. 1. Histology slides 1 (hematoxylin-eosin staining, immunohistochemical staining)

Explanations: Fig. 1A - Amazon parrot, skin, squamous cell carcinoma, keratin pearls (arrows), HE. Fig. 1B - Blue and yellow macaw, liver, cholangiocarcinoma, tubular structures (arrows), HE. Fig. 1C - Amazon parrot, skin, squamous cell carcinoma, neoplastic cells showing intracytoplasmic reactivity for pan cytokeratin. Streptavidin-biotin, hematoxylin counterstain. Fig. 1D - Blue and yellow macaw, cholangiocarcinoma, neoplastic epithelial cells showing intracytoplasmic reactivity for pan cytokeratin. Streptavidinbiotin, hematoxylin counterstain.

frequently observed renal neoplasm in captive and free-ranging birds (17). It is particularly common in budgerigars $(2,16)$ and was found in 3 budgerigars in this study. Highly anaplastic cells forming solid patterns in large areas and mitotic figures were common.

Abdominal carcinoma was diagnosed in 2 birds. Both tumors were located in the cranial abdominal area, attached to the proventriculus. Histologically, they both had epithelial cells showing high pleomorphism. Tumor cells had formed adenoid structures, and the number of mitotic figures was high.

The other types diagnosed were basal cell carcinoma, uropygial carcinoma (Fig. 1B), cloacal carcinoma and cholangiocarcinoma.

In all epithelial tumors, pan-cytokeratin exhibited positive immunoreactivity, with staining intensity changing from weak to strong, and vimentin staining was negative in all of them (Fig. 1C and 1D).

Four different types of mesenchymal tumors were diagnosed in the study. Hemangioma and hemangio- sarcoma were diagnosed in 7 birds. The histological findings were consistent with cases previously reported in the avian literature $(6,12)$. Positive staining with vimentin and von Willebrand Factor (factor VIII), although not very strong, confirmed the histological diagnosis. To the author's knowledge, there are two avian case reports of hemangiosarcoma in which diagnosis is supported by immunohistochemistry $(8,14)$. In both of them, von Willebrand Factor (factor VIII) showed positive reaction in neoplastic endothelial cells.

Fibrosarcoma was diagnosed in 4 birds on histological examination. They all showed positive reaction with vimentin. However, two of them were re-diagnosed as leiomyosarcoma due to their positive reaction with desmin, HHF35 and SMA. Especially SMA staining was very diffuse and strong. As Bonel et al. (4) suggested, leiomyosarcoma has to be taken into consideration in the differential diagnosis of fibrosarcomas in birds. 


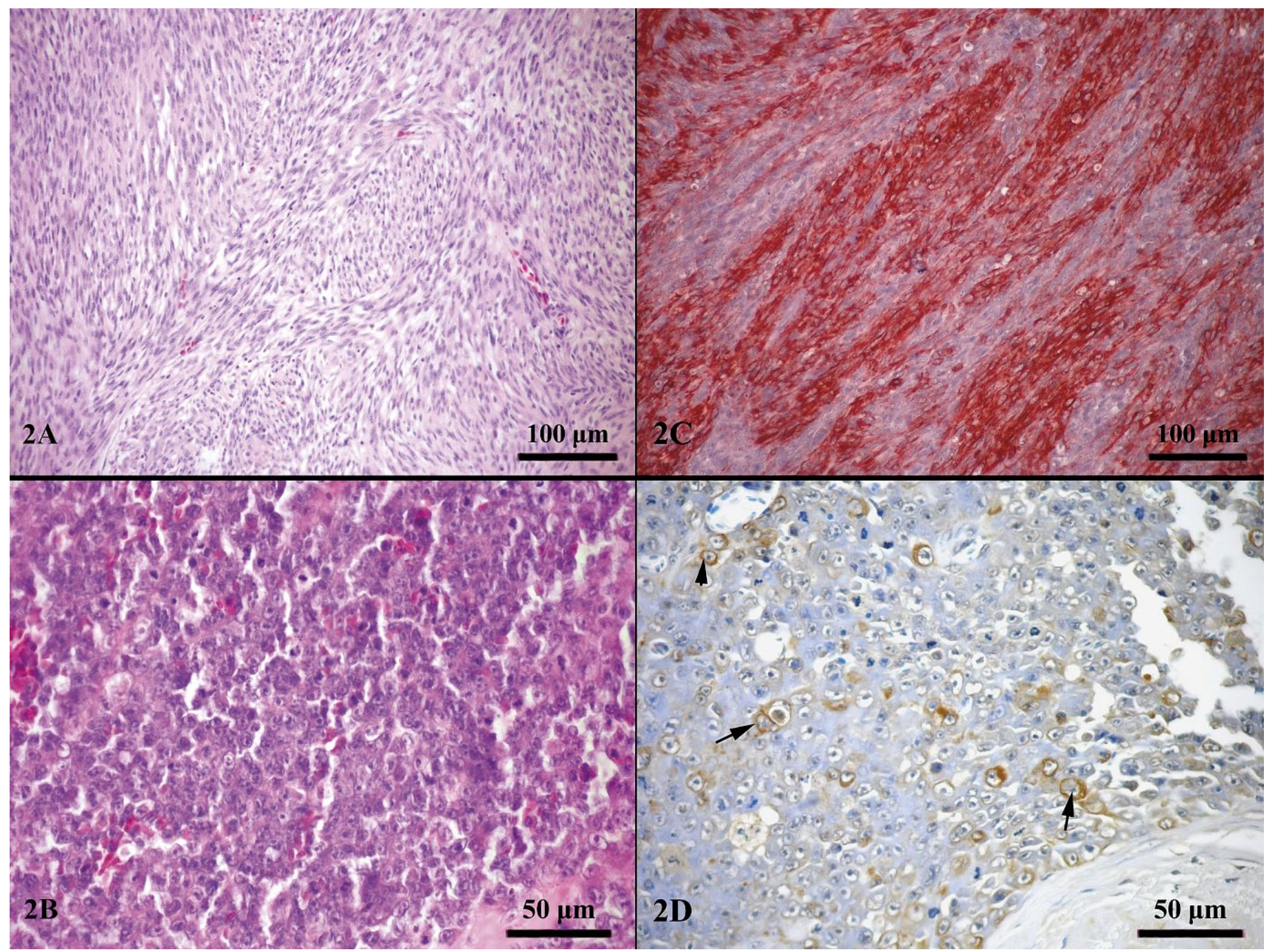

Fig. 2. Histology slides 2 (hematoxylin-eosin staining, immunohistochemical staining)

Explanations: Fig. 2A - Green winged macaw, large intestine, leiomyosarcoma, HE. Fig. 2B - African grey parrot, base of tail, undifferentiated malign tumor, HE. Fig. 2C - Green winged macaw, leiomyosarcoma, neoplastic cells showing strong reactivity for SMA. Streptavidin-biotin, hematoxylin counterstain. Fig. 2D - African grey parrot, anaplastic carcinoma, neoplastic cells showing intracytoplasmic reactivity for pan cytokeratin. Streptavidin-biotin, hematoxylin counterstain.

Leiomyosarcoma has been described in birds quite often $(5,19)$, and in the present study, it was diagnosed in 2 birds on histological examination (Fig. 2A). They were positive for vimentin, desmin, SMA and HHF35. SMA reaction was very strong and diffuse (Fig. 2B). A previous report confirmed a histological diagnosis of cutaneous leiomyosarcoma in a budgerigar with strong positive immunostaining for desmin and SMA (20). It is reported in the veterinary literature that SMA marker is specific and confidently used for tumors that show smooth muscle differentiation in dogs (2), and it is counted for birds as well.

Histological diagnosis could not be made for 7 birds, and they were diagnosed with undifferentiated malignant tumors (UDMT). All of them had highly atypical cells forming irregular and intersecting bundles, whirls and islets. The mitotic index of one case was higher than 20 per ten 40X fields (Fig. 2C).

Out of the seven UDMTs, one was immunopositive for pan-cytokeratin and was re-diagnosed as anaplastic carcinoma (Fig. 2D). Three of them were immu- nopositive to vimentin, desmin and SMA, and were re-diagnosed as leiomyosarcoma. One showed positive staining only for vimentin and was re-diagnosed as fibrosarcoma. Two did not give positive staining with any of the markers and remained unclassified.

Immunohistochemistry helped to make a diagnosis in five of the seven UDMT cases and proved to be of great value.

The characteristic histological features of tumors in the present study correlate well with those of tumors previously described in birds. Only a limited number of antibodies were used in the control panel. However, they were very useful in establishing a definite diagnosis in some cases. It is believed that further studies with more tumor tissues and more specific antibodies will provide more information and make a contribution to the avian literature.

\section{References}

1. Bauck L.: Neoplasms. Diseases of Cage and Aviary Birds. Williams-Wilkins, Philadelphia 1996, 476-478. 
2. Bettini G., Morini M., Marcato P. S.: Gastrointestinal spindle cell tumours of the dog: histological and immunohistochemical study. J. Comp. Pathol. 2003, 129, 283-293.

3. Blackmore D. K.: The clinical approach to tumors in cage birds-I. J. Small. Anim. Pract. 1966, 7, 217-223.

4. Bonel J., Alberti T. S., Stumm G. K. F., Gamba C. O., Bandarra P.,Cassali G. D.: Leiomyosarcoma in a cockatiel. Cienc. Rural. 2019, 1-4.

5. Cardoso J. F. R., Levy M. G. B.: Pathological and Immunohistochemical Diagnosis af an Intestinal Leiomyosarcoma in a Zebra Finch. Braz. J. Vet. Pathol. 2014, 7, 89-92.

6. Latimer K. S.: Avian Medicine. Principles and Application. Wingers Publishing, Lake Worth 1994, p. 640-670.

7. Murtaugh R. J., Ringler D. J., Petrak M. L.: Squamous cell carcinoma of the esophagus in an Amazon parrot. J. Am. Vet. Med. Assoc. 1986, 188, 872-873.

8. Nakano $Y$., Une $Y$ : Hemangiosarcoma with Widespread Mestatasis that Originated on the Matatarsal Pad of a Java Sparrow (Padda oryzivora). J. Vet. Med. Sci. 2012, 74, 621-623.

9. Pye G. W., Carpenter J. W., Goggin J. M., Bacmeister C.: Metastatic squamous cell carcinoma in a salmon-crested cockatoo (Cacatua moluccensis). J. Avian Med. Surg. 1999, 13, 192-200.

10. Ramis A., Gibert X., Majo N., Grifols J.: Metastatic oral squamous cell carcinoma in a Montagu's harrier (Circus pigargus). J. Vet. Diagn. Invest. 1999, 11, 191-194.

11. Reavill D.: A review of psittacine squamous cell carcinomas submitted during 1998-2001. Proc. of Ann. Con. Eu. Assoc. Avian Veterinary 2003, p. 237-240.

12. Reece R. L.: Observations on naturally occuring neoplasms in birds in the state of Victoria. Australia. Avian Pathol. 1992, 21, 3-32.

13. Riddell C., Cribb P. H. E.: Fibrosarcoma in an African grey parrot (Psittacus erithacus). Avian Dis. 1982, 27, 549-555.
14. Rossi G.: A poorly-differentiated hepatic haemangiosarcoma in an Amazona farinosa parrot. Avian Pathol. 1998, 27, 427-430.

15. Schmidt R. E., Quesenberry K.: Avian Medicine and Surgery. W. B. Saunders, Philadelphia 1997, 234-237.

16. Simova-Curd S., Huder J. B., Boeni J., Robert N., Hatt J. M.: Investigations on the diagnosis and retroviral aetiology of renal neoplasia in budgerigars (Melopsittacus undulatus). Avian Pathol. 2010, 39, 161-167.

17. Simova-Curd S., Nitzl D., Mayer J., Hatt J. M.: Clinical approach to renal neoplasia in budgerigars (Melopsittacus undulatus). Small Anim. Pract. 2006, 47, 504-511.

18. Tell L. A., Woods L., Mathews K. G.: Basal cell carcinoma in a blue-fronted Amazon parrot (Amazona aestiva). Avian Dis. 1997, 41, 755-759.

19. Timurkaan N., Eroksuz H., CevikA., Karabulut B.: Cutaneous leiomyosarcoma with osteoid metaplasia in a budgerigar (Melopsittacus undulatus): a case report. Vet. Med. Czech. 2016, 61, 533-537.

20. Zamani-Ahmadmahmudi M., Nassiri S. M., Khaksar E., Solati A. A.: A rare case of cutaneous leiomyosarcoma in budgerigar (Melopsittacus undulatus). Arch. Razi. Inst. 2015, 70, 57-60.

21.Zehnder A., Graham J., Reavill D. R., Mclaughlin A.: Current Therapy in Avian Medicine and Surgery. Elsevier, Missouri 2016, 107-141.

22.Zehnder A. M., Swift L. A., Sundaram A., Speer B. L., Olsen G. P., Hawkins M. G., Paul-Murphy J.: Clinical features, treatment, and outcomes of cutaneous and oral squamous cell carcinoma in avian species. J. Am. Vet. Med. Assoc. $2018,252,309-315$

Corresponding author: Ozge Erdogan Bamac, PhD, DVM, Istanbul University - Cerrahpasa, Faculty of Veterinary Medicine, Department of Pathology, 34320 Avcilar, Istanbul, Turkey; e-mail: oerdogan@istanbul.edu.tr 